\title{
Modelagem ambiental e uso da inteligência artificial para prognóstico de desmatamento: o caso da Rebio do Gurupi-MA
}

Environmental modeling and use of artificial intelligence for prognosis of deforestation: the case of Rebio do Gurupi-MA

Modelización ambiental y uso de inteligencia artificial para el pronóstico de la deforestación: el caso de Rebio do Gurupi-MA

Luana Helena Oliveira Monteiro Gama ORCID: https://orcid.org/0000-0002-5744-5583 Universidade Federal do Pará, Brasil E-mail: eng.luanamonteiro@gmail.com

Paula Fernanda Pinheiro Ribeiro Paiva ORCID: https://orcid.org/0000-0001-8458-3132 Universidade Federal Rural da Amazônia, Brasil E-mail: engpaulapinheiro@gmail.com

Orleno Marques da Silva Júnior ORCID: https://orcid.org/0000-0002-1173-1429 Universidade Federal do Amapá, Brasil E-mail: orlenomarques@yahoo.com.br

Maria de Lourdes Pinheiro Ruivo ORCID: https://orcid.org/0000-0002-6222-5534 Museu Paraense Emilio Goeldi, Brasil E-mail: ruivo@museu-goeldi.br

\begin{abstract}
Resumo
As áreas protegidas foram criadas principalmente para a conservação da biodiversidade na Amazônia. No entanto, existem altas taxas de desmatamento dentro das mesmas, ocasionado pela concessão de estradas, assentamentos e ocupações. O uso de técnicas de geoprocessamento é de suma importância para detectar mudanças no uso e ocupação do solo. Tal estudo objetiva modelar cenários futuros na Reserva Biológica Gurupi-MA no software DINAMICA EGO, usando o método de transição para simular trajetórias de desmatamento até 2030, com base nas variáveis: altitude, declividade, estradas, assentamento e hidrográfica. Como resultado da matriz de transição, quatro transições foram computadas: floresta para desmatamento, floresta para extração ilegal de madeira, extração ilegal de madeira para desmatamento e exploração ilegal de madeira. As áreas da classe florestal apresentaram maior número de células com alteração, com um percentual de $0,25 \%$ de desmatamento e $6,08 \%$ de células para exploração ilegal. Constatouse que vários fatores contribuem para o aumento do desmatamento próximo a estradas e assentamentos: extração ilegal de madeira, criação de gado, caça e ocupação humana, comprometendo a fauna e a flora da região. A partir da simulação do cenário futuro (2030), observou-se que a classe de desmatamento tende a crescer ao norte de REBIO. Até 2030, pode haver uma redução total de 9,17\% da cobertura florestal nesta UC. Por meio da modelagem ambiental, juntamente com os planos de comando, controle e monitoramento, é possível orientar o desenvolvimento socioeconômico e ambiental em áreas protegidas da Amazônia maranhense, para a manutenção e proteção de sua riqueza natural.
\end{abstract}

Palavras-chave: Análise espacial; Desmatamento; Amazônia.

\begin{abstract}
Protected areas were created mainly for the conservation of biodiversity in the Amazon. However, there are high rates of deforestation within them, caused by the concession of roads, settlements and occupations. The use of geoprocessing techniques is of paramount importance to detect changes in land use and occupation. This study aims to model future scenarios in the Gurupi-MA Biological Reserve using the DYNAMIC EGO software, using the transition method to simulate deforestation trajectories until 2030, based on the variables: altitude, slope, roads, settlement and hydrographic area. As a result of the transition matrix, four transitions were computed: forest for deforestation, forest for illegal logging, illegal logging for deforestation and illegal logging. The forest-class areas showed the highest number of cells with changes, with a percentage of $0.25 \%$ deforestation and $6.08 \%$ of cells for illegal exploitation. It was found that several factors contribute to the increase in deforestation close to roads and settlements: illegal logging, cattle raising, hunting and human occupation, compromising the region's fauna and flora.
\end{abstract}


From the simulation of the future scenario (2030), it was observed that the class of deforestation tends to grow north of REBIO. By 2030, there may be a total reduction of $9.17 \%$ in forest cover in this UC. Through environmental modeling, together with the command, control and monitoring plans, it is possible to guide socioeconomic and environmental development in protected areas in the Amazon region of Maranhão, for the maintenance and protection of their natural wealth.

Keywords: Spatial analysis; Deforestation; Amazon.

\section{Resumen}

Las áreas protegidas fueron creadas principalmente para la conservación de la biodiversidad en la Amazonía. Sin embargo, existen altos índices de deforestación dentro de ellos, provocados por la concesión de caminos, asentamientos y ocupaciones. El uso de técnicas de geoprocesamiento es de suma importancia para detectar cambios en el uso y ocupación del suelo. Este estudio tiene como objetivo modelar escenarios futuros en la Reserva Biológica Gurupi-MA utilizando el software DYNAMICS EGO, utilizando el método de transición para simular trayectorias de deforestación hasta 2030, en base a las variables: altitud, pendiente, caminos, asentamiento y área hidrográfica. Como resultado de la matriz de transición, se calcularon cuatro transiciones: bosque para deforestación, bosque para tala ilegal, tala ilegal para deforestación y tala ilegal. Las áreas de clase forestal presentaron el mayor número de celdas con cambios, con un porcentaje de $0.25 \%$ de deforestación y $6.08 \%$ de celdas para explotación ilegal. Se encontró que varios factores contribuyen al aumento de la deforestación cerca de caminos y asentamientos: tala ilegal, ganadería, caza y ocupación humana, comprometiendo la fauna y la flora de la región. A partir de la simulación del escenario futuro (2030), se observó que la clase de deforestación tiende a crecer al norte de REBIO. Para el 2030, puede haber una reducción total de $9.17 \%$ en la cobertura forestal en esta UC. A través de la modelización ambiental, junto con los planes de comando, control y seguimiento, es posible orientar el desarrollo socioeconómico y ambiental en las áreas protegidas de la región amazónica de Maranhão, para el mantenimiento y protección de sus riquezas naturales.

Palabras clave: Análisis espacial; Deforestación; Amazonas.

\section{Introdução}

A floresta amazônica brasileira abrange mais de 3,2 milhões de quilômetros quadrados, protegendo quase um terço das florestas tropicais do mundo, um quinto das águas doces superficiais, desempenhando assim função essencial na regulação do clima regional e global (Uhl, et al., 1997; Veríssimo, 2012). Além disso, o Brasil é o maior produtor de madeira tropical do mundo, e maior parte dessa produção provém da Amazônia, ao qual representa $80 \%$ da renda bruta do setor florestal regional (Veríssimo, 2006; Veríssimo \& Pereira, 2014).

Duas características fazem da Amazônia o principal alvo da Iniciativas de REDD (Redução de emissões decorrentes do desmatamento e da degradação de florestas). Um é que ela possui a maior floresta tropical do mundo, com biomassa equivalente a cerca de 1,5 décadas de antropogênicas emissões de carbono (Soares-Filho, et al., 2006). Outra característica é que, o Brasil tem as maiores parcelas de desmatamento total do mundo, quase um quinto das emissões globais de $\mathrm{CO}_{2}$ (dióxido de carbono) decorrentes da mudança no uso da terra (Borner, et al., 2015).

Apesar da floresta amazônica ser importante constituinte da biosfera global, que beneficia a população internacional, apoiando diversos serviços ecossistêmicos (Daily, 1997), e por ser o lar de 15\% das espécies do mundo, há contínua degradação pelo acelerado desmatamento, que é esperado continuar apesar das políticas para mitiga-lo. Atualmente, o financiamento internacional para proteger a floresta amazônica se concentra em benefícios da redução das emissões de carbono (Siikamaki, et al., 2019).

A partir da década de 1970, o bioma Amazônia teve seu encadeamento de apropriação e desmatamento acelerado, mediante à tentativa de uma agregação nacional, ascendendo o desmatamento a grandes índices, particularmente na área intitulada "arco do desmatamento"1 (Barros \& Barbosa, 2015). Tal processo foi iniciado com a abertura de estradas que possibilitaram a instauração de ocupações divergentes, e principalmente a ampliação do uso do solo nas adjacências das unidades de conservação (Costa, et al., 2015).

\footnotetext{
${ }^{1}$ Região que apresenta maiores índices de desmatamento, fica ao sul da Amazônia, vão do sudeste do Pará para o oeste, passando pelo Norte do Mato Grosso, Rondônia e Acre (Bonini, et al., 2014).
} 
A maior parte do desmatamento acontece próximo às estradas, ao qual facilita o escoamento de recursos naturais primários. Segundo Alves (2010), 90\% do desmatamento ocorre dentro dos $100 \mathrm{~km}$ das estradas principais. Em distâncias de $50 \mathrm{~km}$ de estradas o valor de desmatamento foi entre 67\% e 85\% (Nepstad, et al., 2001; Chomitz \& Thomas, 2001). Sendo assim, a rede de transportes pode desempenhar significativo impacto ambiental futuro (Fearnside, 2007; Fearnside \& Graça, 2006; Kirby, et al., 2006; Laurance, et al., 2006; Laurance, et al., 2001; Laurance, et al. 2002; Silva Junior, 2019), facilitando também as práticas de desmatamento na região amazônica.

A região nomeada de vale do Gurupi, localizada no oeste do Maranhão, formada pela REBIO do Gurupi, TI Alto Rio Guamá, TI Alto Turiaçu, TI Awá e TI Caru, configura um corredor ecológico de grande importância para a conservação da biodiversidade (Almeida \& Vieira, 2010).

Na REBIO do Gurupi, aponta-se a presença significativa da fauna silvestre, dentre aves, répteis e mamíferos de grande porte, tais como anta (Tapirus terrestris), guariba (Alouatta belzebul) e onça-pintada (Panthera onca), principalmente nas áreas de remanescentes de vegetação nativa (classe 01) e áreas de vegetação modificada (classe 02), caracterizando regiões de grande interesse para a conservação da fauna e flora locais, e de todo o ambiente desta área (Hessel \& Lisboa, 2015).

De acordo com o Sistema Nacional de Unidades de Conservação da Natureza - SNUC, ao qual define-se pela Lei $\mathrm{n}^{\circ}$ 9.985, de 18 de julho de 2000, art. $7^{\circ}$, a Reserva Biológica do Gurupi está inserida ao grupo de Unidade de Conservação de Proteção Integral, e tem como objetivo "preservar a natureza, sendo admitido penas o uso indireto dos seus recursos naturais, com exceção dos casos previstos nesta lei (Brasil, 2000).

Segundo Bezerra et al. (2018), a constituição e inserção de Unidades de Conservação (UCs) tem sido uma das possibilidades estratégica para a salvaguardar a biodiversidade. Contabiliza-se que as áreas protegidas com unidades de conservação ocupam 14,13\% da área terrestre e 26,36 \% da área global oceânica, e armazenam 56\% do carbono terrestre global, ajudando assim a minimizar o desmatamento (MMA, 2019).

Uma das principais preocupações do presente estudo são os avanços desordenados de desmatamento e seus altos índices em UCs na Amazônia. De acordo com o INPE (2016) entre os anos de 2012 a 2015, mais de 237,3 mil hectares foram desmatados dentro dessas áreas protegidas. A REBIO do Gurupi ocupa a $8^{a}$ posição de área mais desmatada com incremento de desmatamento acumulado de $1.89 \%$ (INPE, 2019).

Além do mais, existem inúmeras ocupações irregulares no interior e na área de amortecimento da REBIO do Gurupi. Segundo Pinheiro (2019) residem na área e praticam caça, extração de madeira, criam gado, configurando atividades ilegais. Ocasionando inúmeros conflitos entre colonos, grileiros, garimpeiros e sem terras (Caracciolo, 2013).

A paisagem da REBIO do Gurupi constitui estágios continuados de regeneração natural, por vias de remoção e intermediada por áreas abertas ocupadas por assentamentos, vilarejos, fazendas de pecuária e agricultura e atividade de exploração madeireira, propiciando a fragmentação e degeneração ambiental (Hessel \& Lisboa, 2015).

Desta maneira, faz-se necessário a aplicação de métodos para detectar e estimar perdas florestais, que podem servir como complemento às técnicas já existentes. A modelagem ambiental mostra-se acessível para tais análises. O ambiente de modelagem no DINAMICA EGO proporciona simplicidade, flexibilidade, desempenho, otimização e velocidade, e aumento da capacidade computacional (Rodrigues, et al., 2007). Estes modelos incluem simulação baseada em autômatos celulares, ao qual se mostra eficiente em representar e simular a complexidade dos processos envolvidos na dinâmica espacial e na mudança de uso e ocupação do solo (Delaneze, et al., 2014).

Os padrões computacionais e matemáticos estabelecem uma ferramenta bastante utilizada na análise dos processos naturais relacionados as ações antrópicas, contribuindo para a tomada de medidas preventivas, essencialmente a modelagem ambiental baseia-se em descrever o que ocorre na natureza fundado em um modelo investigativo, planejado com base nos dados de investigação do sistema real (Piga, 2017). O software utilizado no estudo mostrou-se eficiente, pois pode-se inserir 
diversas variáveis que irão descrever e prognosticar pixel a pixel as características da área de estudo.

A utilização de técnicas de sensoriamento remoto e geoprocessamento é de suma importância para a detecção e identificação de mudanças de uso e ocupação do solo, a fim de possibilitar a tomada de decisão adequada para determinada área de estudo, com o intuito de executar medidas cabíveis a favor da conservação e preservação da biodiversidade em áreas protegidas, e combate ao desmatamento na Amazônia.

$\mathrm{O}$ presente estudo tem como objetivo modelar cenários futuros a partir de técnicas de sensoriamento remoto e geoprocessamento na Reserva Biológica do Gurupi nos anos de 2010 (inicial) e 2018 (final). Utilizando variáveis em software técnico de sistemas ambientais por meio de Inteligência Artificial. Assim também como, aplicar o modelo no DINAMICA EGO usando o método de transição para simular trajetórias de desmatamento nesta área protegida até 2030, detectando e estimando perdas florestais.

\section{Metodologia}

\subsection{Caracterização da área de estudo}

A área de estudo compreende a Reserva Biológica do Gurupi, Unidade de Conservação (UC) Federal, cuja gestão é realizada pelo Instituto Chico Mendes de Conservação da Biodiversidade (ICMBio), criada em 12 de janeiro de 1988 pelo Dec. $n^{\circ} 95.614$ (IBAMA, 2018). Possui área de 2698.463,82 km², e está localizada no noroeste do Maranhão (Figura 1). Segundo o ISA (2019) esta UC compreende áreas do Município de Centro Novo do Maranhão (56,45\%), Bom Jardim (39,88\%) e São João do Caru $(3,67 \%)$.

Figura 1 - Localização da Reserva Biológica do Gurupi Maranhão - MA.

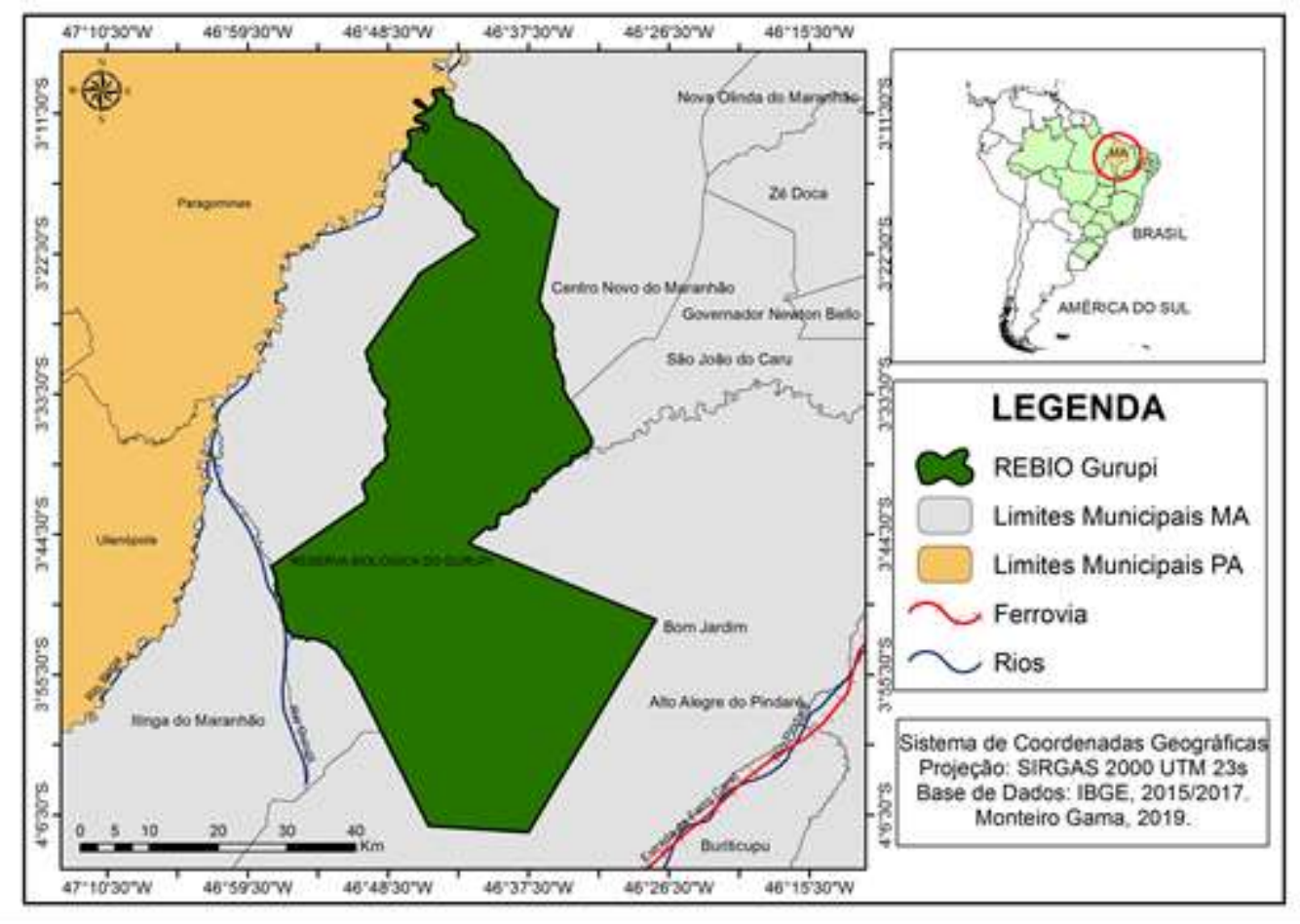

Fonte: Autores (2021).

O estado do Maranhão, pertencente à Amazônia Legal, localizado entre as regiões Norte, Nordeste Centro-Oeste do Brasil, apresenta cobertura vegetal essencial para a sobrevivência das espécies, e vem apresentando dados preocupantes quanto à preservação de seus ecossistemas (Gerude, 2013). Segundo Pinheiro, et al. (2013) a REBIO do Gurupi é a única unidade de 
conservação desta categoria em área amazônica a leste do Rio Xingu, tendo fundamental importância na conservação ambiental do estado do Maranhão, por estar entre os domínios do bioma Amazônia, Cerrado e Caatinga. No entanto, apresenta elevado grau de desmatamento e fragmentação florestal, e um dos menores indicadores de desenvolvimento humano (Simonian \& Baptista, 2015). Possui aproximadamente $107.000 \mathrm{~km}^{2}$ de áreas protegidas, distribuídos entre 10 Unidades de Conservação Estaduais, 11 Unidades de Conservação Federais e 17 Terras Indígenas (Gerude, 2013; ISA, 2019).

Segundo a classificação de Koppen predomina o clima tropical quente e úmido (As). Identifica-se grandes unidades de relevo, tais como: chapadões $(8,44 \%)$, chapadas e cuestas; superfície marinha com testemunhos; golfão maranhense; lençóis maranhenses; litoral em "rias" (IBAMA, 1999; IBGE, 2019). As declividades variam de $2^{\circ}$ a $45^{\circ}$, e os topos caracterizado entre mínima de 20 a 300 metros de altitude, com superfícies aplainadas retocadas ou degradadas (IMESC, 2019).

A região da Amazônia maranhense é dividida entre as bacias hidrográficas dos rios: 1) genuinamente maranhenses: Pindaré (à oeste da REBIO), Turiaçu (à 2241 oeste da REBIO), Maracaçumé, e Pericumã; 2) limítrofes: Tocantins e Gurupi, este último na divisa da REBIO, limite oeste da UC, é também o limite entre os Estados do Maranhão e do Pará. (Miranda et al., 2017). As presentes bacias designam restrições sazonais com relação à disponibilidade das águas (Costa, et al., 2011).

De acordo com os dados do IBGE (2019), o estado do Maranhão possui predominantemente em seu tempo geológico da era Fanerozoico Mesozoica Cretácio (38,83\%), composto por rochas sedimentares, e na porção noroeste onde situa-se a Rebio do Gurupi, contém basicamente rochas de origem ígnea e metamórfica (CNUC, 2016).

A região apresenta solos do tipo Latossolo Amarelo (23,21\%), Plintossolo Pétrico $(6,88 \%)$ e solos aluviais (MMA, 2016 \& IBGE, 2019). E devido a alta umidade e acumulação em horizontes pedogenéticos, há é uma alta ocorrência de solos tropicais elevadamente intemperizados (Costa, et al., 2016). Por esse motivo a referente região de estudo apresenta papel fundamental para a conservação da diversidade biológica da Amazônia Maranhense.

A vegetação da área é de transição (Brasil, 2011), com predominância da Floresta Ombrófila Densa Submontana, representando 3,10\% da região onde localiza-se a REBIO do Gurupi, e possui 17,08\% de vegetação secundária (IBGE, 2019). Sua riqueza florística indica a peculiaridade deste remanescente florestal, que serve de espaço ecológico para diversas espécies da fauna silvestre, figurada por mamíferos, répteis e aves, apresentando espécies ameaçadas de extinção ou com redução de disposição geográfica (Hessel \& Lisboa, 2015).

\subsection{Composição da base de dados}

O método geral da pesquisa foi realizado através de revisão bibliográfica e estudo da relação do homem com a natureza através de análise quantitativa (Koche, 2011; Pereira, et al., 2018). A composição e levantamento da base de dados consiste em informações referentes as variáveis explicativas que compõem a modelagem, mapas temáticos de uso e cobertura do solo, bases vetoriais para geração da variável de distância e variáveis categóricas, assim também como variáveis matriciais de declividade e altitude, como mostra a Tabela 1. 
Tabela 1 - Base de dados originais utilizadas na pesquisa.

\begin{tabular}{|c|c|c|c|}
\hline Base de dados & Fonte & $\begin{array}{c}\text { Ano de } \\
\text { publicação }\end{array}$ & $\begin{array}{l}\text { Represe } \\
\text { ntação }\end{array}$ \\
\hline Unidade de Conservação & $\begin{array}{l}\text { Ministério do Meio } \\
\text { Ambiente (MMA) }\end{array}$ & 2015 & Vetorial \\
\hline Limites Municipais & $\begin{array}{c}\text { IBGE (Instituto Brasileiro de } \\
\text { Geografia e Estatística) }\end{array}$ & 2015 & Vetorial \\
\hline Curva de nível & $\begin{array}{l}\text { Instituto Nacional de Pesquisas } \\
\text { Espaciais (INPE) }\end{array}$ & 2019 & Matricial \\
\hline Estradas & $\begin{array}{l}\text { IBGE (Instituto Brasileiro de } \\
\text { Geografia e Estatística) }\end{array}$ & 2015 & Vetorial \\
\hline Ferrovias & $\begin{array}{c}\text { Departamento Nacional de } \\
\text { Infraestrutura de Transportes } \\
\text { (DNIT) }\end{array}$ & 2015 & Vetorial \\
\hline Hidrografia & $\begin{array}{l}\text { ANA (Agencia Nacional } \\
\text { das Águas) }\end{array}$ & 2017 & Vetorial \\
\hline Bacia Hidrográfica & $\begin{array}{l}\text { ANA (Ágencia Nacional } \\
\text { das Águas) }\end{array}$ & 2017 & Vetorial \\
\hline Assentamentos & $\begin{array}{l}\text { Instituto Nacional de Colonização } \\
\text { e Reforma Agrária (INCRA) }\end{array}$ & 2017 & Vetorial \\
\hline $\begin{array}{l}\text { Imagem de satélite } \\
\text { LANDSAT - } 5\end{array}$ & $\begin{array}{c}\text { USGS (United for States } \\
\text { Geological Survey) }\end{array}$ & 2010 & Matricial \\
\hline $\begin{array}{l}\text { Imagem de satélite } \\
\text { LANDSAT - } 8\end{array}$ & $\begin{array}{l}\text { USGS (United for States } \\
\text { Geological Survey) }\end{array}$ & 2017 & Matricial \\
\hline
\end{tabular}

Fonte: Autores (2021).

Com exceção da base vetorial de estradas (ramais), aos quais foram extraídas manualmente através da criação de shapefile de linha no software ARCGIS 10.5. Para tal extração de vetores, utilizou-se como base a imagem de satélite Landsat de 2019 da USGS, assim como também a plataforma eletrônica Google Earth, as quais facilitaram a visualização dos ramais na área de estudo, sendo possível obter a base de dados de estradas de forma atualizada. Tal conjunto de informações foram projetados para o sistema UTM-Fuso 23, hemisfério Sul.

\subsection{Aquisição de dados}

A partir do conhecimento e investigação das principais características da área de estudo, como base complementar, realizou-se a investigação e obtenção de dados em relação a REBIO do Gurupi, assim como, a seleção de imagens de satélite Landsat 5 e 8, sensores OLI (Operational Terra Imager) e TM (Thematic Mapper), de órbitas/pontos 222/62 e 222/63, para os anos de 2010 e 2018, respectivamente aos satélites, apresentando resolução espacial de 30 metros. Utilizou-se as bandas OLI 6, 5 e 4 e TM 5, 4 e 3. Tais imagens foram adquiridas na página eletrônica da United for States Geological Survey (USGS), entre os períodos de junho e agosto, ao qual levou-se em consideração $10 \%$ de nuvem para ambos os períodos.

Fez-se necessário o pré-processamento das imagens, ao qual realizou-se a correção atmosférica e calibração geométrica nas bandas espectrais das cenas, aplicando-se o método avançado de correção, no modelo físico MODTRAN implantado no aplicativo Fast Line-of-sight Atmospheric Analysis of Spectral Hypercubes (FLAASH) do software ENVI5.3.

\subsection{Análise de uso e ocupação do solo}

Para a análise de uso e ocupação do solo na área de estudo, o processamento foi executado no software ENVI 5.3, em que se registrou no Sistema de Informações Geográficas (SIG) todos os dados presentes nas imagens de satélite, e foram analisadas por etapas diferentes, de maneira que se produziu todas as informações referentes à cobertura vegetal a partir do uso 
e ocupação do solo, com base no Manual Técnico de Uso da Terra (IBGE, 2013). Os shapefiles dos limites municipais e da Unidade de Conservação foram adquiridos na base cartográfica do IBGE.

Aplicou-se o método supervisionado de classificação de Máxima Verossimilhança (MAXVER) para mapear as áreas. Que segundo Leite \& Rosa (2012); Silva, et al. (2011) o classificador MAXVER é um algoritmo paramétrico que agrega classes levando em consideração pontos individuais e atribui a essas classes a distribuição normal, definidos a partir de uma amostra de pixel adquirida, tal algoritmo computa a probabilidade estatística de um pixel desconhecido da imagem, envolvendo estimativas de valores médios de cada classe, a análise é feita pixel a pixel.

As classes estabelecidas para melhor compreensão e análise técnica foram: Floresta, exploração florestal e desmatamento. a) As florestas são áreas onde a cobertura do solo é predominantemente composta por vegetação arbórea; b) A exploração Florestal são áreas submetidas a retirada de vegetação, com predomínio da cor verde e presença de feições circulares de cor magenta, com padrão geométrico definido, assim como também padrão geométrico desordenado. c) E o desmatamento são áreas compostas por limites bem definidos entre o polígono e a matriz florestal, de cor magenta forte, textura lisa e forma regular, evidenciando claramente solo exposto.

Na etapa de avaliação da classificação, ao qual inseriu-se a imagem classificada e os vetores de avaliação, que possuem o rótulo de cada uma das amostras indicando o nome da classe, foi utilizado a ferramenta Confusion Matrix Using Ground Truth ROIs que se encontra no subdiretório pós classificação do ENVI5.3, ao qual gerou o Índice Kappa e obteve-se a exatidão global e acurácia da classificação.

Para a base vetorial de estradas (ramais), extraiu-se manualmente o shapefile de linha no software ARCGIS. Para tal extração de vetores, utilizou-se a imagem de satélite Landsat de 2019 da USGS, assim como também a plataforma eletrônica Google Earth, as quais facilitaram a visualização dos ramais na área de estudo, sendo possível obter a base de dados de estradas de forma atualizada. Tal conjunto de informações foram projetados para o sistema UTM-Fuso 23, hemisfério Sul.

Foram também utilizados como variáveis de entrada os mapas de declividade e altitude, ao qual foram calculados no software ARCGIS. Para a criação do Modelo Digital de Elevação (MDE) utilizou-se o interpolador de triangulação da ferramenta Create TIN do ArcToolbox, a partir da curva de nível.

Realizou-se a conversão das bases vetoriais em matriciais no SIG QGIS 3.8. Ao qual é uma etapa de elevada importância, visto que visa evitar erros no processo de modelagem no software DINAMICA EGO. É imprescindível que todos os dados e variáveis de entrada para simulação do modelo estejam convertidos de vetor para raster no formato GeoTIFF, com a mesma resolução de pixel, o mesmo número de linhas e colunas e sistema de referência.

Posteriormente, para alguns vetores como: estradas, assentamentos e hidrografia foram estabelecidos buffers de 200 metros (Kawashima, 2015) para cada variável, sendo necessário para definição de distância e melhor estudo na escala de trabalho no processo de modelagem.

A conversões padrões estabelecidos para serem empregadas foram determinadas com base nos valores do raster que compreende a área de interesse, definida em 15 metros, correspondendo ao valor do pixel da imagem de satélite Landsat 5 e 8. Todavia, todas as bases matriciais obedeceram a mesma resolução de pixel, linhas e colunas.

\subsection{Modelagem com o DINAMICA EGO}

O presente trabalho embasou-se em estudos de Soares-Filho, et al. (2002), Soares-Filho, et al. (2009), Kawashima (2015), dentre outros, que realizam análise de modelagem e desmatamento na Amazônia. O modelo de simulação foi rodado por oito cenários, em passos anuais, utilizando-se o software DINAMICA EGO (Environment for Geoprocessing Objects), ao qual aplicou-se o modelo LUCC (Land Use and Cover Change), que emprega o método de pesos de evidências, onde 
precisam-se ter como entrada tais pesos de evidência que representam o efeito de uma variável espacial na mudança de uso e ocupação do solo (Vitel, 2009).

O DINAMICA EGO possibilita desde a composição de modelos espaciais estáticos simples até modelos dinâmicos complexos, os quais podem abranger influencias ocultas, retroalimentações dinâmicas, abordagem multirregionais, manipulação e combinação algébrica de dados em vários formatos, como mapas, tabelas, matrizes, e uma sucessão de algoritmos espaciais complexos para a análise e simulação de fenômenos espaço-temporais (Soares-Filho, et al., 2009).

$\mathrm{O}$ ambiente que este software proporciona contém um encandeamento de operadores denominados functors, onde o mesmo é programado a operar uma tarefa específica, e também pode ser entendido como uma técnica que atua sobre um conjunto de dados de entrada, ao qual é aplicado um número limitado de cálculos, gerando como saída um conjunto de dados inovadores. Existem ainda, os operadores de grupos conhecidos como containers.

Os containers compilam e determinam um comportamento para o conjunto de operadores contidos no mesmo. Como por exemplo, os operadores "Repeat", que compartilha a execução do submodelo inserido no modelo. O "Block" que agrega functores, e o "Region", que aplica para que uma determinada operação atinja apenas uma região especifica em um mapa (Rodrigues, et al., 2007).

A princípio, os mapas de distância foram elaborados no próprio software DINAMICA EGO, fundamentado nos dados matriciais de entrada e do functor "Calc Distance to Feature Map". Segundo Soares-Filho (1998) e Kawashima, et al. (2015), o software produz um mapa de distância euclidiana de centroide a centroide a uma distância que é dada em unidade de célula. Os mapas de distância gerados no presente estudo para as variáveis foram: assentamentos, estradas e hidrografia. Outro dado principal é o recorte (limite) da área de estudo, que entra e interage como "máscara" para delineamento do mapa de saída.

Ao executar o programa, os mapas de distância elaborados como saída a partir da ferramenta "Save Map" no modelo, são de distancias à assentamentos (MAPA_DISTANCIA_ASSENTEMENTOS) distância às estradas (MAPA_DIST_ESTRADA) e distância à hidrografia, referentes aos cursos d'água (MAPA_DIST_HIDROGRAFIA).

Como regra para execução do modelo dinâmico, as classes de uso e cobertura do solo são representadas por códigos (números), as quais são: Floresta (código 1); desmatamento (código 2); e exploração florestal (código 3). Visto que os dados de referência em arquivo raster não aceitam inúmeras quantidades de informações nas células, e a descrição de valores equivalentes a cada classe simplifica os procedimentos na elaboração de equações e a modelagem no DINAMICA EGO, ao qual o software interpreta as informações em feições numéricas (Marques, 2019).

Em seguida realizou-se a construção do modelo Cubo Raster, o mesmo é formado usando os functors: "Load Map", "Creat Cube Map" e um "Save Map", nessa etapa foram inseridas as variáveis selecionadas para o modelo já citadas acima. Gerou-se a matriz de transição ao qual calcula-se as matrizes históricas de transição entre as classes, pelo qual tem como resultado uma tabela de com valores de percentual de modificações entre as classes estipuladas em passos simples (single step). Segundo Soares-Filho, et al. (2009), a matriz de transição expõe um sistema que é modificado em incrementos de tempos discretos, nos quais os valores de qualquer variável em um estipulado período de tempo, é determinado como a soma das porcentagens fixas de valores de todas as variáveis inseridas no modelo, e as somas das frações ao longo da coluna da matriz é igual a 1 (um), e suas taxas são transferidas para o modelo LUCC.

A etapa de composição dos intervalos de pesos de evidência é responsável por calcular os intervalos que irão categorizar as variáveis contínuas de tons de cinza para derivar os Pesos de Evidência. Esses intervalos são calculados de forma semelhante a um fatiamento de acordo com a estrutura dos dados. Tal método gera os mapas de probabilidade de transição, que descreve as áreas mais propícias a mudanças (Soares-Filho, et al., 2002). Na sequência realizou-se o cálculo dos coeficientes dos pesos de evidência das variáveis, determinados pelo container "Determine of Weights of Evidence Coefficients" com relação a uma transição ou um conjunto de transições. 
A análise de correlação entre os pesos de evidência foi realizada por intermédio do functor "Determine Weights of Evidence Correlation" do DINAMICA EGO, que Segundo Soares-Filho, Rodrigues \& Costa (2009) engloba os métodos Cramer, que utiliza a estatística qui-quadrado, e a Incerteza da Informação Conjunta (Join Information Uncertaint), que pertence à classe de medidas de entropia, mas também pode ser utilizada para medir associações entre tabelas de contingência. Estes testes fornecem uma medida padronizada que varia entre 0 (zero) e 1 (um), quanto mais próximo de 1 maior a associação entre as variáveis.

Na etapa de configuração do e execução do modelo de simulação LUCC, é inserido no DINAMICA EGO a matriz de transição "multiple-step" calculada na primeira etapa, para calcular as taxas brutas e quantidades de células alteradas no modelo. E a partir das configurações de execução são gerados os mapas de probabilidades e o mapa final simulado (2018), para fim de comparação com o mapa real (2018) ao qual foi classificado no presente estudo. Além da matriz de transição, os dados de entrada inseridos neste modelo, são as variáveis a partir do arquivo tiff de cubo raster, o mapa inicial do ano de 2010, e o arquivo "weights.dcf” de pesos de evidências.

Para a validação das simulações do modelo disponível no DINAMICA EGO, foram aplicadas as medidas de similaridade de Fuzzy, em função da incerteza da localização de uma classe em sua vizinhança local, com objetivo de identificar a similaridade entre os padrões espaciais do mapa simulado (2018) e o mapa real (2018) utilizado como referência. Tal ajuste tem decaimento exponencial com a distância para aferir e assemelhar a distribuição de classes de células ao redor de uma célula central (Godoy \& Soares-Filho, 2007). O mapa resultante desse processo descreve apenas as células que foram modificadas. Foi utilizado o menor valor de similaridade, pois os mapas aleatórios tendem a produzir um ajuste artificialmente alto, quando comparados, eles espalham as mudanças por todo o mapa.

E por fim, é executado o modelo de formação de manchas e simulação de cenários futuros, responsável pela formação de patche e expander para simulação de cenários paro o ano de 2018, tendo como entrada o mapa inicial de 2010. Os valores de patcher e expander para cada transição foram extraídos no próprio DINAMICA EGO, através do functor "Lm Calc Mean Patch Size And Standard Deviations" ao qual calcula os valores médios das manchas e suas variâncias. Após esta etapa, foi executado o modelo para simular tendências futuras, que é o objetivo principal deste estudo, analisar a dinâmica ocorrida na paisagem até $\mathrm{o}$ ano de 2030.

\section{Resultados}

\subsection{Uso e ocupação do solo}

O resultado da classificação do uso do solo no ano de 2010 apresentou exatidão global de $92 \%$ e índice Kappa de 0,87, a qual mostrou-se com alta qualidade e desempenho da classificação. Para o ano de 2018 obteve-se exatidão global de 94\%, e o índice Kappa calculado foi de 0,91. Ambas as classificações representam classificação excelente segundo Landis e Koch (1977). 
Figura 1 - Mapa de uso e ocupação do solo na Reserva Biológica do Gurupi nos anos de 2010 e 2018.
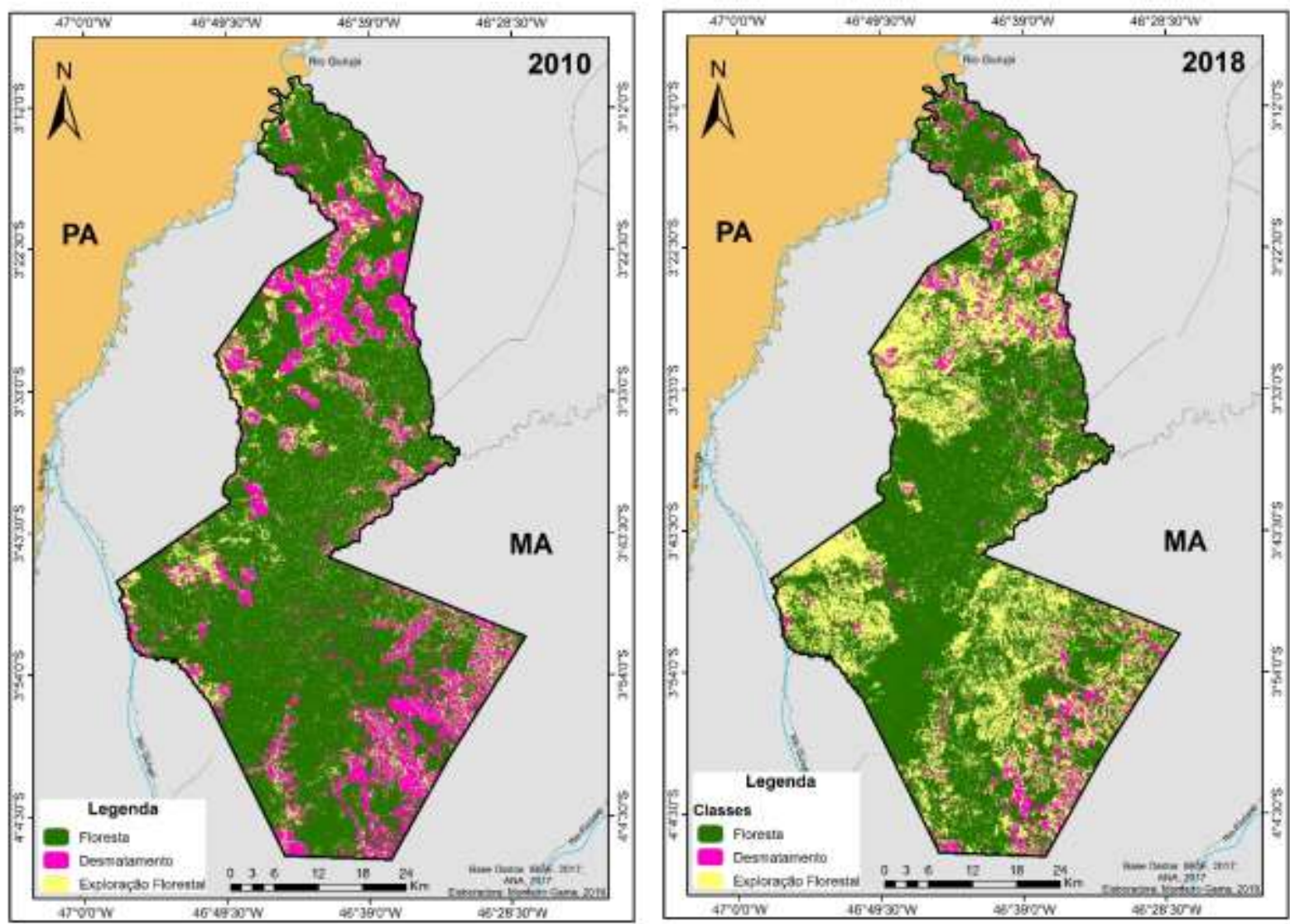

Fonte: Autores (2021).

Os mapas estão representados na Figura 2, tais valores foram utilizados como dados de entrada para simulação do modelo dinâmico, sendo estes, os dados principais para tal estudo.

Tabela 2 - Mudanças de uso do solo entre os anos de 2010 e 2018 na REBIO do Gurupi.

\begin{tabular}{|c|c|c|c|c|c|c|}
\hline \multirow[t]{2}{*}{ Classes } & \multicolumn{2}{|c|}{2010} & \multicolumn{2}{|c|}{2018} & \multicolumn{2}{|c|}{$\begin{array}{c}\text { Mudanças entre os } \\
\text { anos }\end{array}$} \\
\hline & $\mathrm{Km}^{2}$ & $\%$ & $\mathbf{K m}^{2}$ & $\%$ & $\mathbf{K m}^{2}$ & $\%$ \\
\hline Floresta (1) & $1839.717,09$ & 68.17 & $1656.233,62$ & 61.37 & $-183.483,40$ & -19.73 \\
\hline Desmatamento (2) & $474.451,45$ & 17.58 & $193.972,87$ & 7.18 & $-280.478,50$ & -30.16 \\
\hline $\begin{array}{c}\text { Exploração Florestal } \\
\text { (3) }\end{array}$ & $384.295,29$ & 14.24 & $848.257,35$ & 31.43 & $463.962,06$ & 49.89 \\
\hline
\end{tabular}

Fonte: Autores (2021).

A Tabela 2 descreve os valores em $\mathrm{km}^{2}$ para cada classe, assim como também mostra quantitativamente as mudanças que ocorreram entre os anos de 2010 e 2018, e o percentual de área alterada. Os valores positivos indicam que houve aumento da área, como por exemplo, a classe exploração florestal ilegal que apresentou aumento de área de 463.962,06 km², representando $49.89 \%$. Já os valores negativos indicam que ocorreu redução no tamanho da área, como exibe a classe desmatamento com diminuição de área de $280.478,50 \mathrm{~km}^{2}$, tal resultado representa redução de $30.16 \%$ de área desmatada. 


\subsection{Matriz histórica de transição}

A partir da execução do modelo de cálculo da matriz de transição, foram geradas as tabelas correspondentes a matriz de passo simples (Single-step), e a matriz de passos múltiplos (Multiple-Steps). Para o presente estudo, foi utilizado em todo o modelo a matriz de passos múltiplos, que corresponde a taxa anual de transição dentre as classes.

A matriz de transição representa o resultado do cruzamento dos mapas de uso e ocupação do solo do ano de 2010 e 2018, ela exibe a quantidades de células que mudaram de uma classe para outra (Tabela 3), ao qual exibe os valores percentuais das transições entre as classes, utilizada para contabilização das mudanças ocorridas.

Tabela 3 - Matriz com transições "Multiple-Step" e seus valores percentuais.

\begin{tabular}{cccc}
\hline TRANSIÇÃO & Floresta & Desmatamento & Exploração Florestal \\
\hline Floresta & - & $0,25 \%$ & $6,08 \%$ \\
\hline Desmatamento & - & - & $19,88 \%$ \\
\hline Exploração Florestal & $13,35 \%$ & $2,35 \%$ & - \\
\hline
\end{tabular}

Fonte: Autores (2021).

De posse dos resultados da matriz de transição, observa-se que ocorrem cinco transições, as quais são: de floresta para desmatamento (transição 1-2), de floresta para exploração florestal (transição 1-3), de desmatamento para exploração florestal (transição 2-3), esta foi desconsiderada do estudo, de exploração florestal para floresta (transição 3-1) e de exploração florestal para desmatamento (transição 3-2).

As taxas indicam que uma porcentagem da floresta está mudando para área desmatada por unidade de tempo, que é de 8 anos para a primeira matriz, e de 1 ano para a última.

As áreas da classe floresta foram as que mais apresentaram células com mudança, no cenário inicial têm 8227989 células, das quais foram alteradas em percentual de $6,08 \%$ células durante esse período, foram convertidas $0,25 \%$ células para a classe desmatamento, e 6,08 \% células para a exploração florestal. Ou seja, dentro desse período, o desmatamento está ocorrendo a uma taxa líquida de $0,25 \%$ ao ano, e a exploração florestal a uma taxa líquida de 6,08 \%, o que significa que a floresta restante na REBIO do Gurupi está encolhendo a uma taxa total de 6,33 \% ao ano. Os dados revelam ainda taxa total de $25,96 \%$ de exploração florestal ao ano.

\subsection{Pesos de evidência das variáveis}

Um par de pesos, positivo (W+) e negativo (W-) são calculados para cada evidência, neste caso os valores positivos favorecem determinada transição, enquanto valores negativos indicam baixa probabilidade de transição, e valores próximos de zero significam que a variável não exerce efeito sobre a transição (Delaneze, et al., 2011; Soares-Filho, et al., 2009). As transições detectadas foram: de floresta para desmatamento (transição 1-2); floresta para exploração florestal (transição 1-3); exploração florestal para floresta (transição 3-1); e de exploração florestal para desmatamento (transição 3-2). 
Figura 3 - Valores dos pesos de evidência em função das variáveis de transição de floresta para desmatamento. a= distância à altitude; b) distância à estrada; c) distância à assentamento; e d) distância à hidrografia.
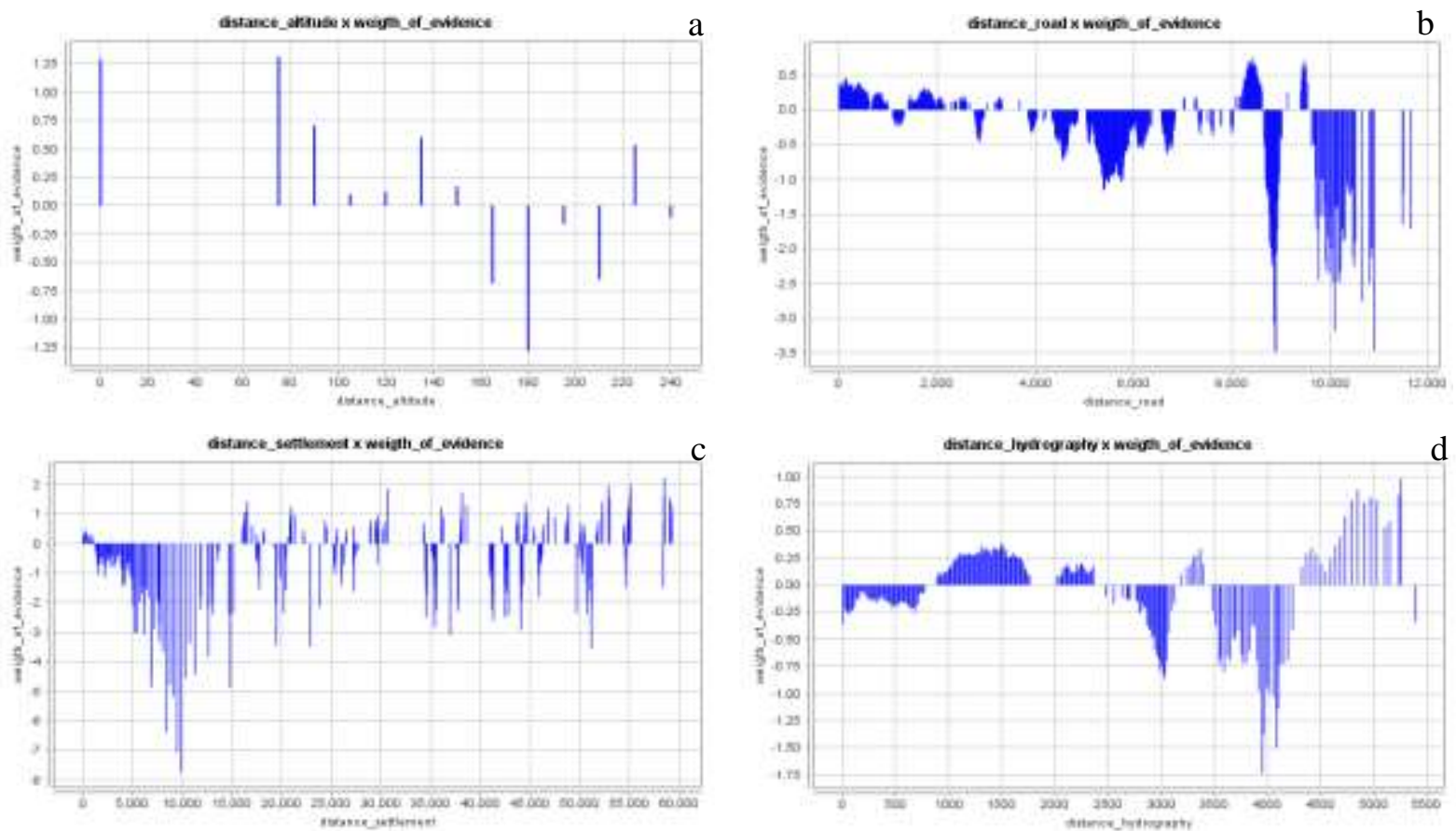

Fonte: Autores (2021).

A transição de áreas florestais para desmatamento apresentou influência positiva com a maior proximidade à hidrografia em até $230 \mathrm{~m}$ de distância (Figura 3a). De acordo com a Figura 3b, houve influência das estradas mais intensamente na faixa de distância até $2 \mathrm{~m}$ e na faixa entre 8 e $9 \mathrm{~m}$. A variável dinâmica de distância à classe assentamento indica que a transição foi influenciada positivamente na faixa de distância até $59 \mathrm{~m}$ (Figura 3c). Em relação à variável hidrografia valor dos pesos de evidência apresentou-se positivo na faixa entre 4.400 e 5.400 m (Figura 3d).

\subsection{Correlação entre os mapas}

A calibração do modelo consiste na verificação da independência entre as variáveis. A análise de correlação entre os mapas gerou os valores referentes ao índice de Crammer e Join Information Uncertainty (Incerteza de Informações Conjuntas), resultante da análise para todas as variáveis consideradas na execução do modelo.

O resultado da análise de correlação pode ser observado na Figura 4, ao qual gerou-se o gráfico a partir do cruzamento dos índices de Crammer e Joint Information Uncertainty obtidos para todas as variáveis. 
Figura 4 - Gráfico de dispersão entre o Índice Crammer e Join Information Uncertainty.

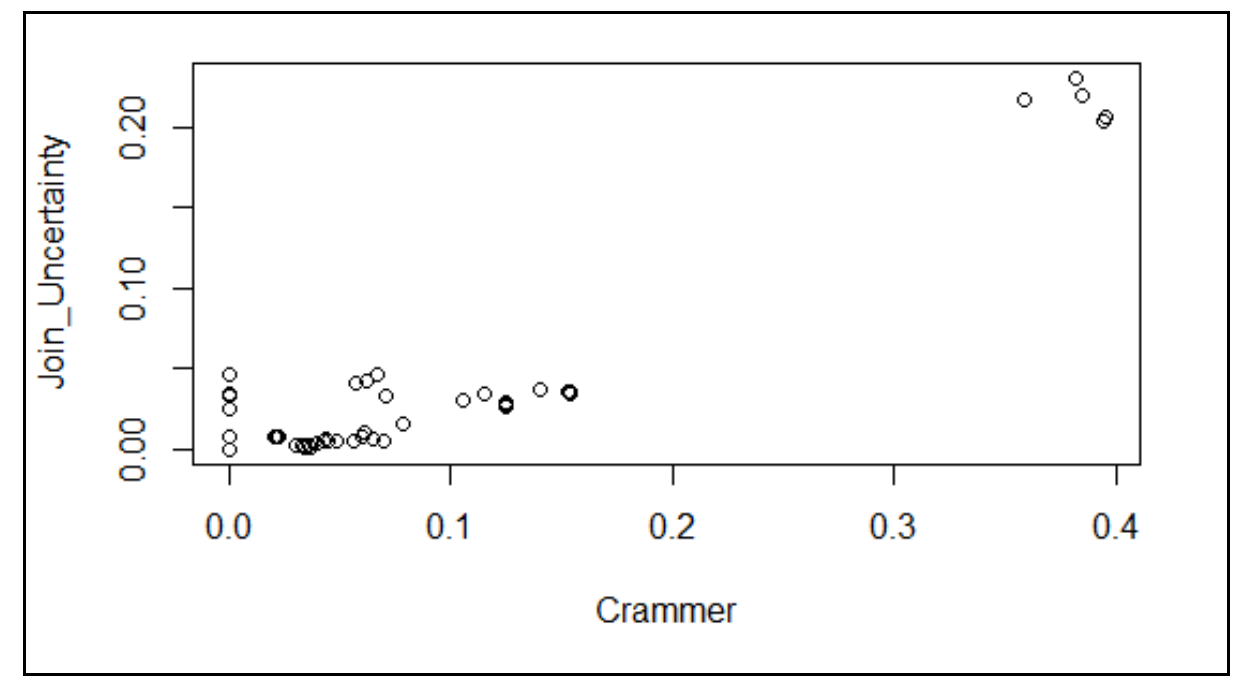

Fonte: Autores (2021).

Constatou-se que nenhum valor ultrapassou 0,50 em ambos os índices (Figura 4). Valores inferiores a 0,5 em tais índices, indicam associação significativa entre pares de variáveis, caso esse valor exceda, uma das variáveis deve ser excluída do modelo, ou ambas combinadas em um único plano de informação para evitar obliquidade no modelo.

\subsection{Probabilidade de transição entre as classes}

Nesta etapa de configuração, a partir da parametrização para simulação do cenário de 2010 a 2018, foram gerados os mapas de probabilidades de transição entre as classes, e o mapa simulado do ano de 2018.

Dentre os mapas de probabilidades, foram escolhidos para discussão dos resultados, os mapas que apresentaram tendência de transição na área de estudo as quais são: mapa de probabilidade de transição floresta/desmatamento; probabilidade de transição floresta/exploração florestal; probabilidade de transição exploração florestal para floresta; e mapa de probabilidade de exploração florestal para desmatamento.

Observa-se que há alta possibilidade de transição de floresta para desmatamento ao norte da REBIO do Gurupi, área em vermelho, que podem estar associadas a implantação de estradas não oficiais, que cortam transversalmente e longitudinalmente esta UC, causando impacto direto a fauna silvestre e a flora local, comprometendo a resiliência e os serviços ecossistêmicos naturais.

\subsection{Validação do modelo}

O resultado alcançado na validação do modelo para a simulação de 2010-2018 foi obtido através de decaimento exponencial, a partir do método de similaridade Fuzzy, executado com o mapa final simulado e o mapa real, exposto na etapa anterior. O modelo foi avaliado tendo como base os valores mínimos de similaridade para cada uma das janelas de amostragem. A partir de janelas com resolução de 1x1 a 11x11 (eixo x). Observou-se que a mínima similaridade de 0,5 está entre as janelas com resolução de $3 \times 3$ e 5x5, com valores 0,5 e 0,6 respectivamente, o que está dentro dos critérios como mostra o gráfico (Figura 5). Nesse processo, é considerado que valores obtidos para mínima similaridade superiores a 0,50 em janelas com resoluções de 3x3 a 5x5 são aceitáveis (Macedo, et al., 2013). 
Figura 5 - Similaridade da paisagem por decaimento exponencial.

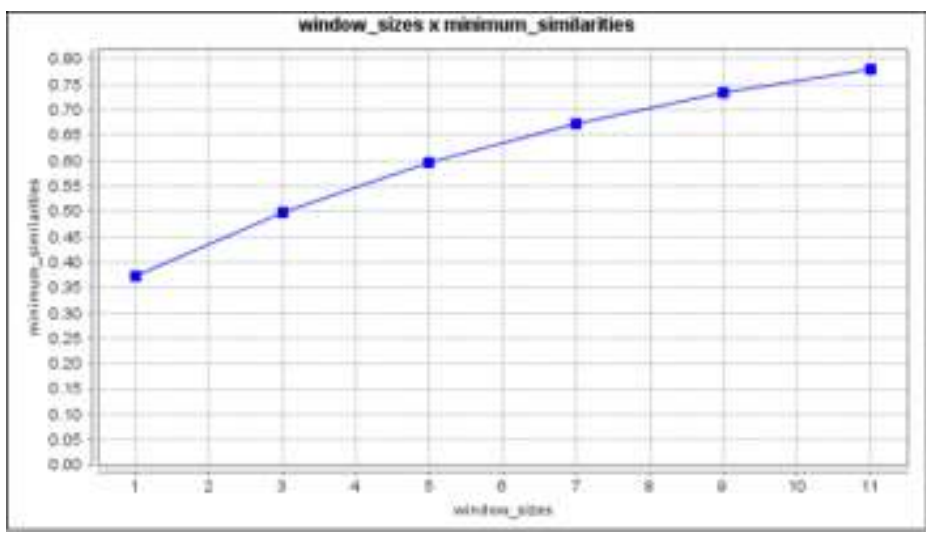

Fonte: Autores (2021).

A simulação atingiu um valor de adequação de similaridade acima de $70 \%$ em uma resolução espacial de 30 metros.

\subsection{Simulação de cenários futuros}

A calibração executada no modelo de formação de manchas patcher e expander, a partir do mapa de 2010, gerou um novo mapa simulado do ano de 2018. Os valores estipulados nas janelas de parâmetros foram fundamentais para controlar o nível de formação e o agrupamento entre as células, fazendo com que o novo mapa simulado de 2018 se assemelhasse ao mapa real de 2018 (Figura 6).

Figura 6 - Mapa simulado (2018) e mapa real (2018).
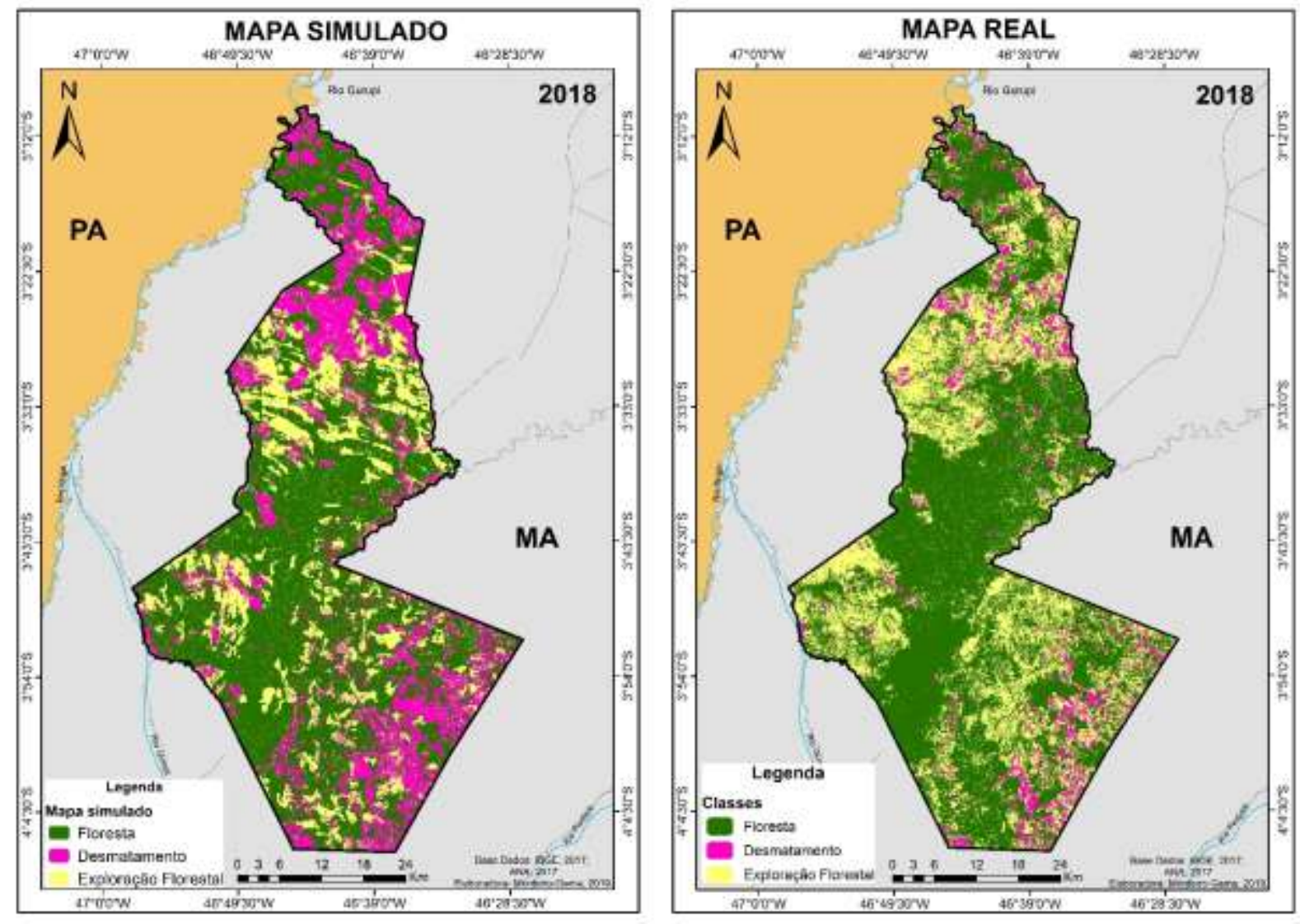

Fonte: Autora (2021). 
De posse da calibração e validação efetivadas para este modelo, com a formação das manchas, foi possível elaborar o mapa de paisagem futura para cada ano, desde o ano de 2018 até 2030. O mapa a seguir mostra a paisagem simulada para o ano de 2030 (Figura 7).

Figura 7 - Mapa de uso e ocupação do solo simulado para o ano de 2030 na REBIO do Gurupi.

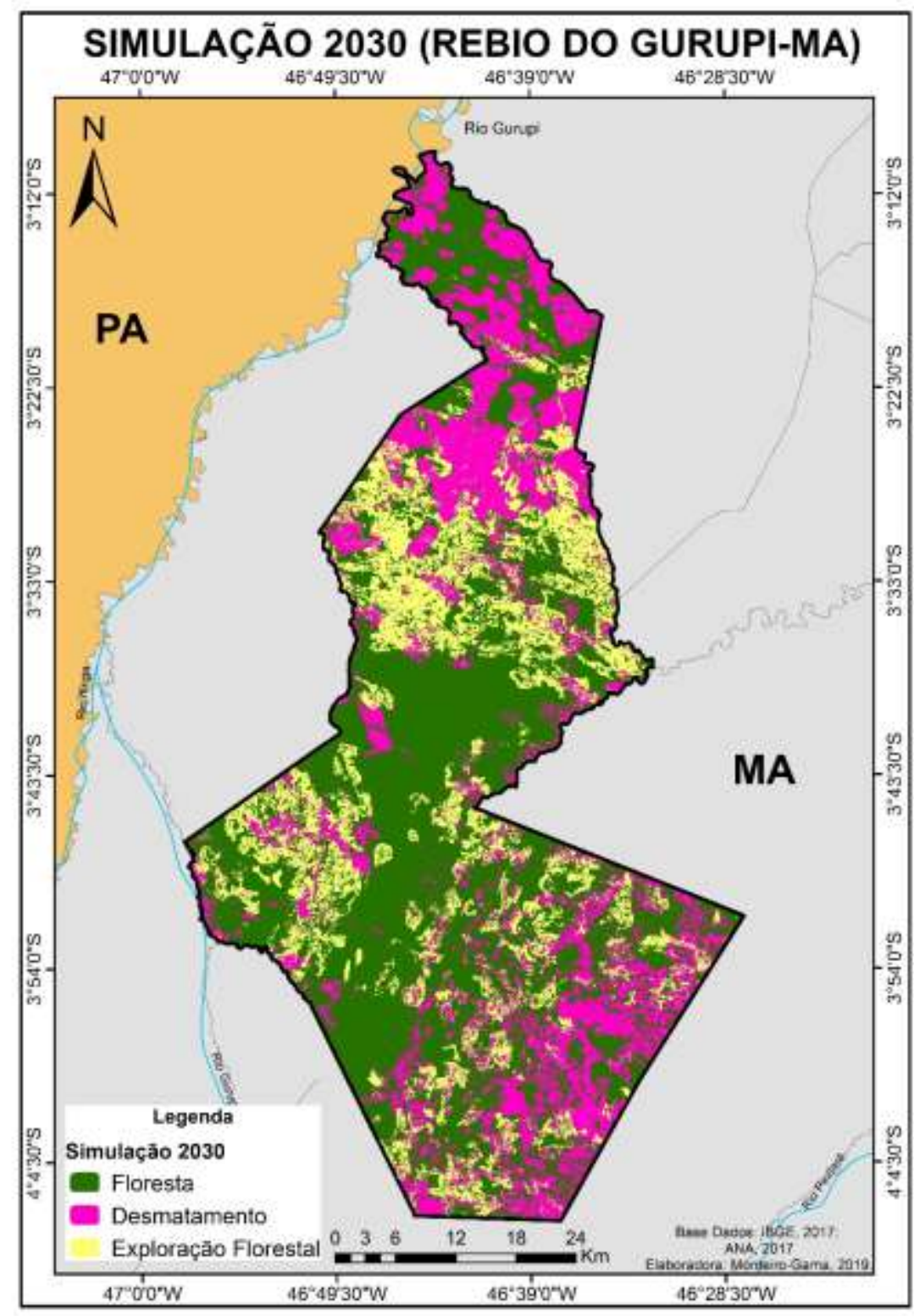

Fonte: Autores (2021).

Os principais fatores apontados são, desmatamento e exploração florestal. Observa-se a partir da simulação de cenário futuro para o ano de 2030 (Figura 4), que a classe desmatamento tende a crescer ao norte da REBIO, área abrangente ao município de Centro Novo do Maranhão, e provavelmente esteja relaciona as estradas irregulares que atravessam a UC, de acordo com o modelo, esses perímetros são considerados mais atraentes para o desmatamento. E também por estar localizada nos limites entre o Pará e o Maranhão, margem esquerda do rio Gurupi, com distância de 59 km da BR-316.

Portanto, já havia uma tendência histórica que favorecia o desmatamento nessa região, elencada pelo projeto da estrada de ferro Carajás, que vai até o porto de Itaqui em São Luís do Maranhão, que provavelmente influenciou sua ocupação. 
A classe floresta tende a perder espaço por conta das transições de floresta para desmatamento e de floresta para exploração florestal, alcançando redução total de 6,33\%.

Os fatores considerados como evidência no estudo, englobam um conjunto de variáveis, as quais foram, os mapas das variáveis estáticas e mapas das variáveis de cobertura do solo, altitude, declividade, distância de estradas, distância de assentamentos e distância de hidrografia.

A partir dos mapas gerados anualmente de 2019 a 2030 (período simulado), selecionou-se os mapas simulados de 2020, 2025 e 2030, com os valores de área de cada uma das 3 classes de uso do solo (floresta, desmatamento e exploração florestal). O resultado obtido pode ser visualizado no Gráfico 2.

Gráfico 2 - Valores em km² das classes de uso e ocupação do solo cenários futuros para os anos de 2020, 2025 e 2030.

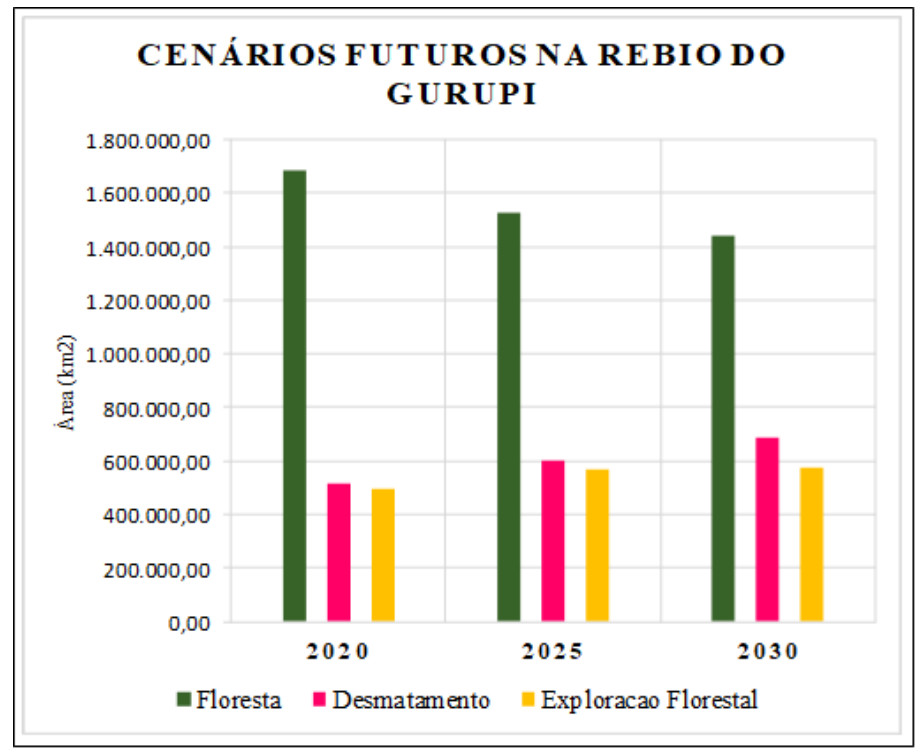

Fonte: Autores (2021).

Observa-se que provavelmente haverá aumento da classe desmatamento entre os períodos analisados, aumento da classe exploração florestal, e consequentemente perda de $1.362 .753,0 \mathrm{~km}^{2}$ de floresta de 2020 a 2025 , assim como, perda de $1.286 .556,4 \mathrm{~km}^{2}$ de área de floresta de 2025 a 2030, representando perda da cobertura florestal de 5,99\% ao ano, e perda total de $9,17 \%$ da classe floresta para os mapas simulados até 2030.

\section{Discussão}

Atualmente, o aumento da capacidade computacional, a maior disponibilidade de dados espaciais e a necessidade de ferramentas de planejamento inovadoras para colaborar na tomada de decisões, fizeram com que houvesse uma aplicação deste modo de modelagem (Brasil \& Klosterman, 2001; Geertman \& Stillwell, 2002). No entanto, a principal desvantagem desse método, é que os mapas de entrada são interdependentes entre eles, e também se torna inviável para áreas extensas (Ferreira, 2009; Delaneze, 2011). Uma das dificuldades para o desenvolvimento do estudo, foi a inclusão de dados de entrada de ocupações que estão no interior da REBIO.

Analisando o perfil histórico da área de estudo, referente ao desmatamento, para Kohllhepp (2002), desde 1970, houve um grande movimento de desenvolvimento econômico em que foram empregadas prática estatais, como construção de estradas, projetos de colonização rural e redução de impostos e ações privadas, como investimentos econômicos em vários 
setores mediante incentivos fiscais e redução de taxas tributárias, para investimento na criação de gado, indústria e projetos de mineração.

Ainda nesse mesmo período, a frente madeireira promoveu uma acelerada devastação da floresta amazônica em sua então fronteira oriental: o oeste e sudoeste do Maranhão, coagida pela construção das rodovias BR-010 e BR-222; pelo crescimento de Açailândia e Imperatriz; pelo Projeto de Colonização Agrícola de Buriticupu; e pela construção da Estrada de Ferro (EF) Carajás (Varga, 2008).

A partir dos anos 90, ampliou a preocupação internacional com a destruição das florestas tropicais, resultando em julho de 1990 na criação do Programa Piloto Internacional para Conservação das Florestas Tropicais Brasileiras (PPG-7), compondo em um conjunto de projetos que possibilitam contribuir para o uso sustentável dos recursos naturais e para a diminuição da taxa de desmatamento (Miranda, et al., 2017).

Entre os anos de 2007 e 2015, as florestas degradadas na REBIO do Gurupi somavam 2,2 mil km², representando 14,4\% das florestas remanescentes nas áreas protegidas (Celentano, et al., 2018). Associados e intensa exploração ilegal de madeira e desmatamento, pois para se ter acesso às árvores de grande valor comercial, os madeireiros constroem uma rede de estradas e ramais (Brandão Junior \& Souza Junior, 2006).

No interior da REBIO é comum a classe degradação, corte seletivo geométrico, corte seletivo desordenado e cicatriz de incêndio florestal, localizadas principalmente ao norte da área de 2012 a 2015 (Miranda, 2014; Miranda, et al., 2017). Segundo Moura, et al. (2011), há grande concentração fundiária por parte de pecuaristas e empresas madeireiras. Miranda, et al. (2017) reiteram que ocorre desmatamento na porção sul da área, próximos aos assentamentos rurais e de pequenos produtores.

Segundo relatório do Ministério do Desenvolvimento Agrário (MDA, 2015) e a Coordenação de Gestão de Conflitos Territoriais do Instituto Chico Mendes de Conservação da Biodiversidade (ICMBio, 2014), no Estado do Maranhão, no período entre 1900 a 2015 foram registrados 288 projetos de assentamento, os quais cobrem uma área de 1.203.461,62 hectares, com capacidade de 40.828 famílias assentadas. Alguns desses espaços estão inseridos na área de amortecimento e na área interna da REBIO do Gurupi, nos limites do município de Bom Jardim. Já segundo o INCRA (2013), o estado do Maranhão possui 802 assentamentos, com 111.513 famílias assentadas, representando 22\% de assentamentos no estado.

O Ministério do Meio Ambiente (MMA) anunciou que em 2008 os projetos de assentamento do INCRA representaram as seis primeiras posições na lista dos agentes causadores de desmatamento na Amazônia (Calandino, et al., 2012). Soares (2008) aponta que além da falta de planejamento territorial, há a falta de conhecimento da legislação ambiental, desrespeitando a Área de Preservação Permanente (APPs) e Reserva Legal (RL), impulsionando assim o desmatamento, ocasionando prejuízos ambientais, tais como: degradação e retração dos remanescentes florestais (Farias, 2018).

Pinheiro, et al. (2019) afirma que na REBIO do Gurupi há conflitos entre INCRA e Instituto de Colonização e Terras do Maranhão (ITERMA), visto que legalizaram projetos de assentamentos dentro da UC, ato este totalmente proibido por lei, por ser esta Unidade de Conservação de Proteção Integral.

O desmatamento, assim também como, a exploração florestal, são predominantes nesta área, com valores superiores a 14\%, a qual se observa um modelo disseminado na distribuição de atividades antrópicas, principalmente a exploração florestal, que promoveu a modificação das florestas primária e secundária que eram predominantes na REBIO do Gurupi em 2008 (Pinheiro, 2019).

Miranda, et al. (2017), reiteram que em 2015, foi verificado um aumento das atividades ilegais na REBIO do Gurupi, com modificações ocasionadas por desmatamento com corte raso de $0,71 \mathrm{~km}^{2}$ de desmatamento, $0,48 \mathrm{~km}^{2}$ de desmatamento com vegetação e $0,50 \mathrm{~km}^{2}$ de degradação. Segundo dados do PRODES (INPE, 2016), nesse mesmo período, a referida UC 
apresentou 29,14 \% de sua área total desmatada. Deixando evidente a fragilidade de fiscalização nessa área para contenção de atividades ilegais na região.

Diante disso, observa-se que vários fatores contribuem para o aumento de desmatamento próximos a estradas e assentamentos. Assim como também contribuem para as modificações ambientais, tais como: desmatamento, queimadas, extração ilegal de madeira, caça e ocupação humana, comprometendo a diversidade biológica existentes na REBIO (Pinheiro, 2019). Além do Projeto da Estrada de Ferro Carajás, outro fator negativo é a pecuária crescente na região, inclusive no interior da REBIO do Gurupi (Pinheiro, et al., 2019).

Atualmente, o uso do solo é o principal causador da perda de biodiversidade no mundo, e sua interferência provavelmente aumentará no futuro (Sala, et al., 2000; Newbold, et al., 2015). A presente análise confirma tal fato, a qual na REBIO provavelmente haverá aumento do desmatamento e diminuição de área florestal até 2030.

Na REBIO do Gurupi, o uso e ocupação do solo ocasionados pela ação humana, acarretam grandes modificações da paisagem neste importante reserva que protege os recursos naturais. Os níveis de degradação no bioma Amazônia pertencente ao Maranhão, obtiveram perda de quase 75\% da cobertura vegetal (Celentano, et al., 2018).

Tais mudanças de uso e ocupação do solo acarretam ao longo dos anos consequências, as quais são, entre outras, a destruição da floresta nativa, perturbação da fauna e flora, fragmentação florestal, mudança de habitat e invasão de espécies exóticas, perda da biodiversidade e impactos climáticos, aumento de vegetação rasteira (Santos, et al., 2011; Rescia et al., 2013; Pinheiro, 2019; Silva, et al., 2019). Sendo assim, a manutenção da área de floresta na REBIO do Gurupi é de fundamental importância para a conservação da biodiversidade tanto local, quanto regional e global.

Segundo Barni, et al. (2018) com a retirada da floresta e dos remanescentes de floresta nativa, pode acarretar perda de estoque de carbono entre 19 e $42 \%$, equivalente a aproximadamente cinco anos de emissão de carbono. A fragmentação florestal por sua vez, altera a área e dinâmica das populações, a composição o processo das comunidades, as interações trófic as e os processos ecossistêmicos (Laurance \& Vasconcelos, 2009), nesse caso deve-se levar em consideração a área do entorno.

O cenário simulado do presente estudo demonstra que até 2030 pode haver perda de 6,28\% na cobertura florestal da REBIO do Gurupi. Esse resultado difere do cenário de linha de base utilizado no cenário business-as-usual (BAU) simulado por Soares-Filho, et al. (2007) para a REBIO. O modelo desenvolvido por esses autores (SimAmazonia) projetou perda na cobertura florestal de $4,86 \%$ até 2030 .

A relação entre o desmatamento e as mudanças climáticas pode ser a maior ameaça à biodiversidade da floresta amazônica, principalmente ao Sudoeste, sul e leste da Amazônia, ao quais são as regiões provavelmente afetadas pelos impactos expressivo do desmatamento e mudança climática, mostrando que a Amazônia Oriental pode sofrer até 95\% de perda de florestas até 2050, seguido pelo sudoeste (81\%) e sul da Amazônia (78\%) (Gomes, et al., 2019).

Examina-se uma justificativa coerente para a conservação e valorização da floresta amazônica para a comunidade internacional, tanto a nível ambiental quanto social, levando em consideração os custos ambientais, conservação viável e econômica. Em estudo realizado Siikamaki, et al. (2019) evidenciou-se que a preservação da floresta amazônica vale \$3.168 (dólares) por hectare (intervalo de confiança de 95 por cento \$1.580- \$ 4.756 (dólares) para a população dos Estados Unidos e Canadá, equivalente ao total de cerca de US $\$ 12$ bilhões por ano. Em uma base por hectares, esta estimativa sugere que o valor de existência da floresta amazônica é de \$ 3.168 por hectares até 2050 (Siikamaki, et al., 2019).

Para Nie, et al. (2018) a população da China que foi entrevistada está disposta a pagar cerca de CNY (Yuan Chinês) 441,66 por proteção ecológica por ano. Ao qual buscar-se compensar o papel das terras agrícolas na garantia de espaços rurais abertos e serviços ecológicos (Wang, et al., 2020).

Diante dos resultados e da discussão apresentada, tal análise é particularmente importante considerando as dificuldades na aplicação de atividades eficientes de prevenção, controle e monitoramento em uma área do tamanho da região 
amazônica (Soares-Filho, et al., 2007; Soares-Filho, et al., 2010; Nepstad, et al., 2014), visto que a REBIO do Gurupi possui área total de $2.698 .463,82 \mathrm{~km}^{2}$.

\section{Considerações Finais}

O uso da Inteligência Artificial acoplada a software computacional em SIG, juntamente com a modelagem tem sido essencial para estudos ambientais, análise espacial, e para o levantamento de dados, diagnosticando as mudanças ocorridas ao longe do tempo, assim como também prognosticar cenários futuros em áreas protegidas na Amazônia.

Constatou-se, que as maiores taxas de transições observadas em toda a área da REBIO do Gurupi, foram as classes floresta e exploração florestal. Ou seja, foram as áreas que mais apresentaram células com mudança, com percentual de $0,25 \%$ de desmatamento, e 6,08 \% células para a exploração florestal. Tais valores significam que a floresta restante na REBIO está encolhendo a uma taxa total de $6,33 \%$ ao ano.

A modelagem para identificação de áreas propícias a abertura de estradas ilegais, é um fator imprescindível para priorizar a elaboração e reorganização de áreas protegidas. Visto que se evidencia a ausência de desenvolvimento de uma política pública voltada para essa divisão, através do entendimento de aspectos sociais, produtivos e ambientais, onde a premissa básica seja minimizar a pressão exercida sobre o meio ambiente, assim também como, coagir as populações residentes nessas áreas, garantindo um padrão sustentável de desenvolvimento.

Portanto, mudanças nas prioridades econômicas do governo brasileiro podem acarretar novas transformações nos padrões de assentamento humano que promovem o desmatamento em áreas protegidas na Amazônia.

Com base nos resultados obtidos, é possível voltar a atenção para pontos estratégicos que tem alta probabilidade de mudanças nos padrões de uso do solo nesta UC, próximos a assentamentos e estradas irregulares, sendo viável elaborar estratégias de conservação da diversidade biológica ainda existente nesta região, assim como delimitar pontos estratégicos de fiscalização como ferramenta de apoio para órgãos competentes.

Diante do que foi abordado, destaca-se a necessidade de um novo estabelecimento de normas para o uso e cobertura do solo em áreas protegidas na Amazônia. O cenário simulado para a REBIO do Gurupi, demonstra que pode haver perda de 5,99\% da cobertura vegetal ao ano, e até 2030 perda total de 9,17\% da área florestal. A qual provavelmente, esta área, estará vulnerável a degradação ambiental.

Evidencia-se então, que através da modelagem, juntamente com um melhor planejamento da paisagem espacial, controle e monitoramento, é possível orientar o desenvolvimento social, econômico e ambiental em áreas protegidas na Amazônia maranhense, para manutenção e proteção de suas riquezas naturais.

Como sugestão para trabalhos futuros, e para melhor compreensão da referida área de estudo, estima-se inserir demais variáveis independentes, como por exemplo, assentamentos, localidades próximas, precipitação e temperatura, que são de grande importância para estudo de sistemas ambientais e socias nessa região.

\section{Agradecimentos}

Ao CNpq pela concessão de bolsa de pesquisa ao primeiro autor. Ao Laboratório de Geoprocessamento, Análise Espacial e Monitoramento por satélite (LAGAM). À Universidade Federal Rural da Amazônia e aos meus orientadores.

\section{Referências}

Almeida, A. S. de \& Vieira, I. C. G. (2010). Centro de Endemismo de Belém: Status da vegetação remanescente e desafios para a conservação da biodiversidade e restauração ecológica. Revista de Estudos Universitários (REU), 36 (3), 95-111. 
Alves, D. S. (2010). Space-time dynamics of deforestation in Brazilian Amazônia. Int. J. Remote Sensing, 23, 2903-2908. https://doi.org/10.1080/01431160110096791

Barni, P., Fearnside, P., Graça, P. A. (2018). Simulando desmatamento e perda de carbono na Amazônia: impactos no Estado de Roraima devido à reconstrução da BR-319 (Manaus - Porto Velho). In: Oliveira SKS, Falcão MT (eds.) Roraima: Biodiversidade e Diversidades. Editora da Universidade Estadual de Roraima (UERR), Boa Vista, Roraima, p. 154-173.

Barros, R. A. \& Barbosa, R. dos S. (2015). Unidades de Conservação: Um estudo sobre os impactos ambientais resultantes da extração de madeira da Reserva Biológica do Gurupi-MA. Inter-Espaço. Revista de Geografia e Interdisciplinaridade, 1 (2), 270-292.

Bezerra, G. S. C. L. et al., 2018. Política Pública e o desafio da participação social na gestão de unidades de conservação. Holos, Ano 34, 06. Doi: $10.15628 /$ holos.2018.4486

Bonham-Carter (1994). Geographic information systems for geoscientists: modelling with GIS. Ontario: Pergamon. 305.

Borner, J., Marinho, E., Wunder, S. (2015). Mixing Carrots and Stickstoff Conserve Forests in the Brazilian Amazon: A Spatial Probabilistic Modeling Approach. PloS one, 10 (2).

Bransão Junior, A. O. \& Souza Junior, C. M. (2006). Mapping unofficial roads with Landsat images: a new tool to improve the monitoring of the Brazilian Amazon rainforest. Int. J. Remote Sens. 27, 177-189.

Brasil. (2000). Website do MMM - Ministério do Meio Ambiente. Lei 9.985, de 18 De Julho de 2000. Institui o Sistema Nacional de Unidades de Conservação da Natureza e dá outras providências. Brasília - DF. 2000. Brasil (2019).

Brasil. (2011). Amazônia Maranhense: Diversidade e Conservação. Organizado por Marlúcia Bonifácio Martins; Tadeu Gomes de Oliveira - Belém: MPEG.

Celentano, D. et al. (2018). Towards zero deforestation and forest restoration in the Amazon region of Maranhao state, Brazil. Land Use Policy. 68. Doi: 10.1016/j.landusepol.2017.07.041

Costa, K. S. P. et al. (2011). Estudo da potencialidade hídrica da Amazônia maranhense através do comportamento de vazões. In Martins, M. B.; Oliveira, T. G. de. Amazônia Maranhense: Diversidade e Conservação. Belém: MPEG, 328 p.: il.

Costa, G. et al. (2015). Ocupações ilegais em unidades de conservação na Amazônia: o caso da Floresta Nacional do Bom Futuro no Estado de Rondônia/Brasil. Revista de Geografia e Ordenamento do Território (GOT), (8), 33-49. http://dx.doi.org/10.17127/got/2015.8.003

Chomitz \& Thomas (2016). Geographic patterns of land use and land intensity in the Brazilian Amazon. World Bank Policy Research Working Paper 2687, Washington DC. 2001.

CNUC. (2019). Website do CNUC - Cadastro Nacional de Unidades de Conservação.

Cruz, et al. (2017). Unidades de conservação no entorno da Bacia de Campos: análise da representatividade e distribuição espacial. In: Lima, S.O.F., editora. Atlas de sensibilidade ambiental ao óleo: caracterização ambiental regional da Bacia de Campos, atlântico Sudoeste. Rio de Janeiro: Elsevier. Habitats, 9, 31 47 .

Delaneze, M. E. (2011). Modelagem dinâmica espacial aplicada na avaliação das mudanças da cobertura da terra no entorno de dutos utilizando autômatos celulares-Estudo de caso duto Orbel. Dissertação de Mestrado, Instituto de Geociências e Ciências Exatas do Campus de Rio Claro, São Paulo, p. 1-116 UNESP.

Daily, G. C. (1997). Nature's Services: Societal Dependence on Natural Ecosystems. Washington, Island Press.

Fearnside, P. M. (2007). Brazil's Cuiabá-Santarém (BR-163) highway: the environmental cost of paving a soybean corridor through the Amazon. Environ. Manage, 39, 601-614

Fearnside, P. M. \& Graça, P. M. L de A. (2006). BR-319: Brazil's Manaus-Porto Velho highway and the potential impact of linking the arc of deforestation to central Amazonia. Environ. Manage. 38, 705-716.

Forzza, R. C. et al. (2012). New Brazilian Floristic List Highlights Conservation Challenges. Revista BioScience, 62, 1, jan.

Gerude, G. R. (2013). Focos de Queimadas em áreas protegidas do Maranhão entre 2008 e 2012. Anais XVI Simpósio Brasileiro de Sensoriamento Remoto SBSR. Foz do Iguaçu-PR.

Godoy, M. M. G. \& Soares-Filho, B. S. (2007). Modelagem da dinâmica de ocupação do solo no bairro Savassi, Belo Horizonte, Brasil. In: Almeida C. M, Câmara, G.; Monteiro, A. M. V. M. Geoinformação em urbanismo: cidade real x cidade virtual. São Paulo: Oficina de textos, cap. 13, $286-304$.

Hessel, F. de O. \& Lisboa, E. A. (2015). Mapa do estado de conservação da Reserva Biológica do Gurupi: Identificação das áreas conservadas e das áreas antropizadas. Anais XVII Simpósio Brasileiro de Sensoriamento Remoto - SBSR, João Pessoa-PB, Brasil, 25 a 29 de abril de 2015 , INPE, 4224-4231.

Ibama. (2018). Website do IBAMA - Instituto Brasileiro de Meio Ambiente e Recursos Naturais Renováveis. Plano de Manejo da Reserva Biológica do Gurupi. Brasília, junho de 1999.

Ibge. (2013). Instituto Brasileiro de Geografia e Estatística. Diretoria de Geociências Coordenação de Recursos Naturais Rio de Janeiro, RJ - Brasil.

Ibge (2019). Website do IBGE - Instituto Brasileiro de Geografia e Estatística. Área Total Brasileira. Brasil: IBGE, 2015.

Imesc. (2019). Instituto Maranhense de Estudos Socioeconômicos e Cartográficos. Sumário Executivo do Zoneamento Ecológico Econômico do Estado do Maranhão - ZEE. Etapa bioma amazônico. Paulo Henrique de Aragão Catunda, Luiz Jorge Bezerra da Silva Dias (organizadores). São Luís: IMESC, 493. 
Inpe. (2019). Website do INPE - Instituto Nacional de Pesquisas Espaciais.

Isa. (2019). Website do ISA - Instituto Socioambiental.

Kawashima, R. S. (2015). Modelagem da dinâmica espacial das mudanças na cobertura da terra na região portuária da Baixada Santista/RS. 190 p. Dissertação de Mestrado. Escola Politécnica da Universidade de São Paulo. Departamento de Engenharia de Transportes.

Kohllhepp, G. (2002). Conflitos de interesse no ordenamento territorial da Amazônia brasileira. Estudos Avançados, São Paulo, 16 (45), $37-61$.

Kochi, J. C. (2011). Fundamentos de metodologia científica: teoria da ciência e iniciação à pesquisa. [e-book]. Petrópolis, RJ: Vozes.

Laurance, W. F. et al. (2001). The future of the Brazilian Amazon. Science, 291, 438-439.

Laurance, W. F. et al. (2002). Predictors of deforestation in the Brazilian Amazon. J. Biogeography. 29, 737.

Laurance, W. F. et al. (2006). Rapid decay of tree-community composition in Amazonian forest fragments. Proc. Natl. Acad. Sci. EUA, 103, $19010-19014$.

Laurance, W. F. \& Vasconcelos, H. (2009). Consequências ecológicas da fragmentação florestal na Amazônia. Oecologia Australis, 13 (3), 434 451. Recuperado em https://revistas.ufrj.br/index.php/oa/article/view/7080/5657

Landis, J. R. \& Koch, G. G. (1977). The measurements of agreement for categorical data. Biometrics, 33 (3), 159-179.

Leite, E. F. \& Rosa, R. (2012). Análise do uso, ocupação e cobertura da terra da bacia hidrográfica do Rio Formiga, Tocantins. Revista Eletrônica de Geografia, 4 (12), 90-106.

Miranda, M. V. C. (2014). Análise multitemporal da dinâmica do uso e cobertura do solo na Reserva Biológica (Rebio) do Gurupi no Estado do Maranhão. Monografia. Universidade Federal Rural da Amazônia, Belém.

Miranda, M. V. C. et al., (2017). Análise temporal das alterações na cobertura florestal na REBIO do Gurupi (Maranhão) utilizando dados do DETER - B de 2012 a 2015. Anais do XVIII Simpósio Brasileiro de Sensoriamento Remoto - SBSR. INPE.

Moura, W. C. et al., (2011). A Reserva Biológica do Gurupi como instrumento de conservação da natureza na Amazônia Oriental. In Martins, M. B. Oliveira, T. G. de. Amazônia Maranhense: Diversidade e Conservação. Belém: MPEG. 328 p.

MMA. (2016). Ministério do Meio Ambiente. Secretaria de Biodiversidade. Cadastro Nacional de Unidades de Conservação. Relatório Parametrizado Unidade de Conservação.

MMA. (2019). Website do MMA - Ministério do Meio Ambiente. Cadastro Nacional de Unidades de Conservação. Unidades de Conservação Brasileiras.

Nepstad, D. C. et al. (2001). Road paving, fire regime feedbacks, and the future of Amazon forests. Forest Ecology and Management, 154, 395-407. Doi: $10.1016 / \mathrm{S} 0378-1127(01) 00511-4$

Newbold T., Hudson, L. N., Hill, S. L. L. et al (2015). Global effects of land use on local terrestrial biodiversity. Nature 520, 45-50. https://doi.org/10.1038/nature14324

Nie, X., Chen, Q., Xiao, T., Wang, H. (2019) Willingness to pay for ecological function regions protection based on a choice experiment method: a case study of the Shiwandashan nature reserve. Qual Quant 53, 813-829. https://doi.org/10.1007/s11135-018-0790-x

Pereira, A. S. et al. (2018). Metodologia da pesquisa científica. Ed. UAB/NTE/UFSM.

Piga, F. G. (2017). Modelagem ambiental de áreas degradadas por processos erosivos, com vista ao planejamento ambiental-São Pedro e Santa Maria da Serra/SP. Dissertação de Mestrado. Universidade Federal de São Carlos.

Pinheiro, P. F. V. et al. (2013). Desmatamento em Unidades de Conservação de Proteção Integral: O caso da Reserva Biológica do Gurupi - MA. Anais XVI Simpósio Brasileiro de Sensoriamento Remoto - SBSR. Foz do Iguaçu-PR.

Pinheiro, P. F. V. (2019). Fragmentação florestal em áreas protegidas na Amazônia maranhense e conservação da biodiversidade. Tese de Doutorado. Programa de Pós-Graduação em Biodiversidade e Biotecnologia, Instituto de Ciências Biológicas, Universidade Federal do Pará, Belém.

Rescia, A., Sanz-Cañada, J., Gonzalez-Cascon, V., González, I. D. B. (2013). Land-use changes and biodiversity conservation in agricultural landscapes. A case study. http://hdl.handle.net/10261/99108

Rodrigues, H. O. et al. (2007). Dinamica EGO, uma plataforma para modelagem de sistemas ambientais. Trabalho apresentado no XIII Simpósio Brasileiro de Sensoriamento Remoto, Florianópolis (SC). In: Anais do XIII Simpósio Brasileiro de Sensoriamento Remoto. São José dos Campos (SP): Instituto Nacional de Pesquisas Espaciais, 30, 89-96.

Sala, O. E., Chapin, F. S., Armesto, J. J. et al. (2000). Global biodiversity scenarios for the year 2100. Science 287, 1770-1774. https://doi.org/10.1126/science.287.5459.1770

Silva, M. G. da, Faro, B. L. S. de O, Almeida, H. P., Morales, G. P., Martins, A. C. C. T., Pontes, A. N. (2019). Aplicação do NDVI para análise espaçotemporal da cobertura vegetal da Reserva Biológica do Gurupi, Maranhão. Educação Ambiental em Ação, n. 68, Ano XVIII, Jun-Ag. http://www.revistaea.org/artigo.php?idartigo=3721

Silva Junior, O. da. et al. (2019). A importância das Áreas Protegidas na Amazônia Brasileira para a Mitigação de Emissões de Gases de Efeito Estufa em Reservatórios Hidrelétricos. In: Silva and Silva (Org.). Produção Espacial e Dinâmica Socioambiental no Brasil Setentrional. 1ed.Belém: GAPTA, 1, 435-457. 
Research, Society and Development, v. 10, n. 2, e13810211609, 2021

(CC BY 4.0) | ISSN 2525-3409 | DOI: http://dx.doi.org/10.33448/rsd-v10i2.11609

Simonian, L. T. L. \& Baptista, E. R. (2015). Formação Socioambiental da Amazônia. Ligia T. Lopes Simonian, Estér Roseli Baptista, Organizadoras. Belém: NAEA, 804 p.: il.; 23 cm - Coleção Formação Regional da Amazônia; 3.

Siikamaki, J. V., Krupnick, A. J., Strand, J., Vincent, J. (2019). International Willingness to Pay for the Protection of the Amazon Rainforest. World Bank Policy Research Working Paper 8775, Available at SSRN: https://ssrn.com/abstract=3360132.

Soares-Filho, B. S. (1998). Modelagem da dinâmica de paisagem de uma região de fronteira de colonização amazônica. Tese de Doutorado. Escola Politécnica, Universidade de São Paulo, São Paulo.

Soares-Filho, B. S. et al. (2002). A stochastic cellular automata model designed to simulate the landscape dynamics in na Amazonian colonization frontier. Ecological Modelling, 154, 217-235.

Soares-Filho, B. S. et al. (2007). Modelagem de dinâmica de paisagem: concepção e potencial de aplicação de modelos de simulação baseados em autômato celular. Megadiversidade, 3 (1-2), 74-76.

Soares-Filho, B. S. et al. (2009). Modeling Environmental Dynamics with Dinamica EGO. Centro de Sensoriamento Remoto (IGC/UFMG) - Universidade Federal de Minas Gerais, Belo Horizonte, MG, Brazil. 114p.

Soares-Filho, B. S. et al. (2010). Role of Brazilian Amazon protected areas in climate change mitigation. Proc. Natl. Acad. Sci., 107, 10821-10826.

Uhl, C. et al. (1997). Natural resource management in the Brazilian Amazon. BioScience, 47, 160-168.

Varga, I. V. D. (2008). A insustentável leveza do estado: devastação, genocídio, doenças e miséria nas fronteiras contemporâneas da Amazônia, no Maranhão. Acta Amazônica, 38 (1), 85-100

Vitel, C. S. M. N. (2009). Modelagem da dinâmica do desmatamento de uma fronteira em expansão, Lábrea, Amazonas. Claudia Suzanne Marie Nathalie Vitel. Dissertação de Mestrado. Programa de Pós Graduação em Ciências de Florestas Tropicais. Manaus, Amazonas.

Veríssimo, A. A. et al (2006). Áreas para produção florestal manejada: detalhamento do macrozoneamento ecológico econômico do estado do Pará. Relatório para o Governo do Estado do Pará.

Veríssimo, A. A. (2012). Amazônia brasileira: desenvolvimento e conservação. In: Trigueiro, A. Mundo Sustentável 2: novos rumos para um planeta em crise. São Paulo: Globo, 203-208.

Veríssimo, A. \& Pereira, D. (2014). Produção na Amazônia Florestal: características, desafios e oportunidades. Parc. Estrat. Brasília-DF, 19 (38), $13-44$.

Wang, Y., Wang, W., Zhang, G. F. (2020). Effects of rapid urbanization on ecological functional vulnerability of the land system in Wuhan, China: A flow and stock perspective. Journal of Cleaner Production, 248 (1), e119284. 